\title{
Períodos de semeadura e condições de armazenamento na qualidade de cozimento de grãos de feijão
}

\author{
Sowing periods and storage conditions in the cooking quality of common bean grains
}

\author{
Nerinéia Dalfollo Ribeiro ${ }^{\mathrm{I}}$ Nerison Luis Poersch ${ }^{\mathrm{II}}$ Simone Saydelles da Rosa ${ }^{\mathrm{III}}$
}

\section{RESUMO}

O objetivo do trabalho foi avaliar o efeito de períodos de semeadura na qualidade de cozimento de grãos de feijão da cultivar "Pérola", armazenados em diferentes condições de temperatura, umidade e tempo de estocagem. O delineamento experimental utilizado foi o inteiramente casualizado, com três repetições. Os tratamentos consistiram da combinação de três períodos de semeadura (15/10/2003, 29/10/2003 e 21/11/2003), três ambientes de armazenamento (temperatura ambiente; temperatura de $12^{\circ} \mathrm{C}$ e umidade relativa de $45-50 \%$; e temperatura de $0,5^{\circ} \mathrm{C}$ e umidade relativa de $80 \%$ ); e três tempos de armazenamento dos grãos (zero, três e seis meses). As porcentagens de grãos normais e de grãos duros apresentaram comportamento diferenciado em função do ambiente e do tempo de armazenamento. A porcentagem de grãos duros foi maior no terceiro período de semeadura. A absorção de água diminuiu após o período de seis meses de armazenamento. O tempo de cozimento dos grãos de feijão não foi alterado com o armazenamento quando as semeaduras foram realizadas em 15/10/2003 e em 29/10/2003. Maior tempo para a absorção de água ou para o cozimento pode ser requerido em função da qualidade dos grãos no momento da colheita ou das condições de temperatura e de umidade de armazenamento.

Palavras-chave: Phaseolus vulgaris L., absorção de água, tempo de cocção, grãos duros, ambiente de armazenamento.

\section{ABSTRACT}

The objective of the research was to evaluate the effect of sowing periods on cooking quality of common bean grains of the 'Pérola' cultivar when stored under different temperatures, moisture content and storage times. A completely randomized design was applied, with three replications. The treatments were combinations of three sowing periods (10/15/ 2003, 10/29/2003 and 11/21/2003), three storage environment (environment temperature; $12^{\circ} \mathrm{C}$ of air temperature and 45 $50 \%$ of moisture content; and $0.5^{\circ} \mathrm{C}$ of air temperature and $80 \%$ of moisture content); and three storage times (0, 3 and 6 months). The percentage of normal and hard grains was influenced by storage environment and storage time. The highest percentage of hard grains was verified in the three sowing period. The water imbibition was decreased after six months of the storage. The cooking time was not varied to storage time when sowings were made in 10/15/2003 and 10/29/2003. Highest time to water uptake and cooking can be necessary in function of the quality grain in moment harvesting or of the temperature and content moisture during storage.

Key words: Phaseolus vulgaris L., water uptake, cooking time, hardshell grains, storage environment.

\section{INTRODUÇÃO}

A rápida absorção de água e o reduzido tempo de cocção dos grãos de feijão conferem qualidade para o cozimento e são determinantes para a aceitação de uma cultivar para o consumo. Essa qualidade, no entanto, pode ser afetada pelo clima principalmente pela ocorrência de alta temperatura do ar no período de enchimento dos grãos, pelas práticas de cultivo e pelo beneficiamento pós-colheita, contribuindo para a manifestação da interação genótipos $\mathrm{x}$ ambientes (SCHOLZ \& FONSECA JÚNIOR, 1999a,b; CARBONELL et al., 2003; DALLA CORTE et al., 2003; LEMOS et al., 2004; RODRIGUES et al., 2005; RIBEIRO et al., 2007).

A temperatura e a umidade relativa do armazenamento afetam a qualidade do feijão para o cozimento, pois maior tempo de cocção se faz necessário à medida que se aumenta o período de estocagem dos grãos (BURR et al., 1968; ROZO et al., 1990). Nesse sentido, BURR et al. (1968) obtiveram incremento do

IDepartamento de Fitotecnia, Centro de Ciências Rurais (CCR), Universidade Federal de Santa Maria (UFSM), 97105-900, Santa

Maria, RS, Brasil. E-mail: neiadr@smail.ufsm.br. Autor para correspondência.

${ }^{\text {IIC }}$ urso de Agronomia, CCR, UFSM, Santa Maria, RS, Brasil.

IIIPrograma de Pós-graduação em Agronomia (PPGA), UFSM, Santa Maria, RS, Brasil. 
tempo de cocção quando o armazenamento dos grãos de feijão foi realizado em temperatura de 21 oC e $18 \%$ de umidade relativa, no período de 12 meses.

$\mathrm{O}$ armazenamento provoca mudanças no sabor, escurecimento do tegumento dos grãos em algumas cultivares e o aumento no grau de dureza dos grãos, o que resulta em acréscimos no tempo de cozimento (SARTORI, 1996). A resistência ao cozimento é causada por diferentes tipos de dureza dos grãos. Assim, o termo hardshell se refere às sementes maduras e secas, que falham em absorver água quando embebidas em períodos relativamente longos (BOURNE, 1967). Enquanto que, hard-to-cook é empregado para descrever a condição na qual os grãos requerem um tempo prolongado de cozimento para amolecer ou não amolecem, mesmo depois de período prolongado em água em ebulição. O hardshell caracteriza impermeabilidade do tegumento à água e o hard-to-cook está associado ao não amolecimento do cotilédone durante a cocção, mesmo que o grão absorva água (BOURNE, 1967; VINDIOLA et al., 1986).

A ocorrência de hardshell é favorecida quando o armazenamento é realizado em temperaturas altas e em baixa umidade relativa do ar e o hard-tocook ocorre em condições de armazenamento em alta temperatura e alta umidade relativa do ar (ROZO et al., 1990; SARTORI, 1996; KIGEL, 1999). O endurecimento dos grãos de feijão tem sido atribuído à ação de polifenóis, por meio de sua polimerização no tegumento ou pela lignificação dos cotilédones, ambos influenciando a capacidade de absorção de água dos grãos. O primeiro dificulta a penetração de água e o segundo limita a capacidade de hidratação (MOURA, 1998). Além disso, espessura, massa, aderência aos cotilédones, elasticidade, porosidade e propriedades coloidais do tegumento interferem na capacidade de hidratação dos grãos de feijão (WYATT, 1977).

Considerando que a conservação adequada pode manter a qualidade de cozimento por maior período de armazenamento, assegurando o valor comercial do produto, o objetivo deste trabalho foi avaliar o efeito de períodos de semeadura na qualidade de cozimento de grãos de feijão da cultivar "Pérola", armazenados em diferentes tempos (zero, três e seis meses) e em condições de temperatura e de umidade (temperatura ambiente; temperatura de $12^{\circ} \mathrm{C}$ e umidade relativa de $45-50 \%$; e temperatura de $0,5^{\circ} \mathrm{C}$ e umidade relativa de $80 \%$ ).

\section{MATERIAL E MÉTODOS}

A semeadura foi realizada em área experimental do Departamento de Fitotecnia, da Universidade Federal de Santa Maria (UFSM), Santa Maria, RS (latitude 2942'S, longitude 5349'W e 95m de altitude). $\mathrm{O}$ clima da região é do tipo $\mathrm{Cfa}$ - temperado chuvoso, com chuvas bem distribuídas ao longo dos anos e subtropical, do ponto de vista térmico.

Os grãos de feijão da cultivar "Pérola", representativa do grupo carioca, foram obtidos em três períodos de semeadura - época 1: 15/10/2003, época 2: 29/10/2003 e época 3: 21/11/2003, utilizando datas em que foi possível realizar a semeadura a campo, considerando principalmente a umidade do solo, durante o período recomendado para o cultivo de safra no Estado do Rio Grande do Sul (CEPEF, 2003).

O solo, classificado como Alissolo Hipocrômico argilúvico típico, foi preparado de forma convencional, com adubação realizada de acordo com a interpretação da análise química, sendo a aplicação de nitrogênio em cobertura, com uréia, parcelada em duas aplicações de $40 \mathrm{~kg} \mathrm{ha}^{-1}$ de nitrogênio, nos estádios vegetativos V3 e V4, respectivamente, de primeira e terceira folhas trifolioladas. Os tratos culturais, como controle de insetos e de plantas infestantes, foram realizados, sempre que necessário, de maneira que não houvesse competição com a cultura.

A colheita manual das plantas foi realizada em três épocas, de acordo com a maturação fisiológica dos grãos: época 1 (16/01/2004), época 2 (26/01/2004) e época 3 (13/02/2004). Os grãos de feijão, após a debulha e a separação das impurezas, em máquinas de ar e peneira, foram secados ao sol e, havendo necessidade, em estufa, até umidade de 12\%, em média, quando os grãos foram acondicionados em sacos de papel, constituindo os tratamentos.

O delineamento experimental utilizado foi o inteiramente casualizado, com três repetições, sendo os tratamentos combinados em fatorial $3 \times 3 \times 3$. Os tratamentos consistiram de: três períodos de semeadura (época 1: 15/10/2003, época 2: 29/10/2003 e época 3: 21/ 11/2003); três condições de armazenamento: a) ambiente - com variação natural da temperatura e da umidade relativa durante o período de avaliação; b) armazenamento em câmara com temperatura média do ar de $12^{\circ} \mathrm{C}$ e umidade relativa de $45-50 \%$ (câmara 1 ); e c) armazenamento em câmara com temperatura média do ar de $0,5^{\circ} \mathrm{C}$ e umidade relativa de $80 \%$ (câmara 2); três tempos de armazenamento dos grãos: zero imediatamente após a colheita, três e seis meses após o armazenamento.

As análises da qualidade de cozimento foram realizadas no Laboratório de Análise de Qualidade da UFSM. A absorção de água foi realizada com 25 grãos de feijão, por repetição. A cada 30 minutos, uma amostra de grãos foi colocada em embebição por oito horas, em copos plásticos com 50mL de água destilada, para composição dos tratamentos (RODRIGUES et al., 2004). Após o tempo pré-determinado, os grãos foram retirados e parcialmente secos em papel toalha e, por meio de contagem manual, se quantificaram as 
porcentagens de grãos normais (com absorção normal de água) e a de grãos duros (sem a capacidade de hidratação) em relação ao número total de grãos avaliados. A porcentagem de absorção de água dos grãos foi determinada pela diferença de massa antes e após a embebição, conforme métodos de GARCIAVELA\& STANLEY (1989) e de PLHAK et al. (1989).

A avaliação do tempo de cozimento dos grãos foi efetuada com o emprego do aparelho cozedor de Mattson, com 25 hastes (PROCTOR \& WATTS, 1987). As amostras de grãos foram previamente embebidas em água destilada por oito horas em temperatura ambiente (RODRIGUES et al., 2004). A seguir, a água foi eliminada e os grãos colocados na placa suporte do aparelho ficando, cada haste, sobre um grão. $\mathrm{O}$ aparelho foi colocado em uma panela com água destilada fervente, mantendo-se o aquecimento. À medida que ocorria o cozimento, as hastes caíam, atravessando os grãos e o tempo decorrido do instante em que o cozedor foi colocado na água fervente até a queda da haste foi utilizado como tempo de cozimento de cada grão. O tempo médio de queda das 13 primeiras hastes foi considerado como tempo médio de cozimento de cada amostra.

Os dados obtidos foram submetidos à análise de variância, utilizando-se o teste $\mathrm{F}$ a 5\% de probabilidade de erro, para testar as hipóteses da interação períodos de semeadura x condições de armazenamento $\mathrm{x}$ tempo de armazenamento e dos efeitos principais. O efeito de períodos de semeadura foi considerado aleatório e os efeitos de condições de armazenamento e tempo de armazenamento, como fixos. Em relação às variáveis com interação significativa, efetuou-se a comparação das médias pelo teste de Duncan a 5\% de probabilidade de erro.

\section{RESULTADOS E DISCUSSÃO}

Na análise de variância, obtiveram-se interações triplas significativas - períodos de semeadura $x$ condições de armazenamento x tempos de armazenamento, para as porcentagens de grãos normais, de grãos duros e de absorção de água (Tabela 1). Já interação dupla significativa - períodos de semeadura $x$ tempos de armazenamento - foi observada para cozimento dos grãos, indicando comportamento diferenciado em função dos períodos de semeadura e do tempo de armazenamento.

As porcentagens de grãos normais e de grãos duros obtidas ao longo do período de armazenamento foram alteradas em função da época de semeadura e das condições de armazenamento (Tabela 2). Quando a semeadura foi realizada em 15/10/ 2003, observou-se uma diminuição da porcentagem de grãos normais aos seis meses após o armazenamento, nas condições de temperatura ambiente e na câmara 1 . A porcentagem de grãos duros - hardshell, por sua vez, aumentou consideravelmente no mesmo período. Esse resultado é diferente do obtido por PLHAK et al. (1989), que utilizando condições aproximadas de estocagem (35\% de umidade relativa do ar e temperatura de $15^{\circ} \mathrm{C}$ ), conseguiram prevenir a dureza dos grãos. No entanto, a ocorrência de grãos hardshell somente foi evitada quando os grãos foram armazenados na câmara 2 (80\% de umidade relativa do ar e temperatura de $\left.0,5^{\circ} \mathrm{C}\right)$.

No segundo período de semeadura (29/10/ 2003), não foram observadas alterações nas porcentagens de grãos normais e de grãos duros, nas diferentes condições de armazenamento e ao longo do período, excetuando-se os grãos armazenados na

Tabela 1 - Graus de liberdade (GL) e quadrado médio para porcentagem de grãos normais (GN), porcentagem de grãos duros (GD), teste de absorção de água (absorção) e tempo de cozimento (cocção) para as causas de variação, média e coeficiente de variação (CV\%) de grãos de feijão da cultivar "Pérola" avaliados em três períodos de semeadura no cultivo de safra, três condições de armazenamento e em três tempos de armazenamento. Santa Maria - RS, UFSM, 2005

\begin{tabular}{|c|c|c|c|c|c|}
\hline \multirow{2}{*}{ Causas de variação } & \multirow[b]{2}{*}{ GL } & \multicolumn{4}{|c|}{----------------------------------------Quadrado médio----------------------------------------- } \\
\hline & & GN & GD & Absorção & Cocção \\
\hline & & \multicolumn{3}{|c|}{---------------------------- \% ---------------------- } & (minutos) \\
\hline Períodos (P) & 2 & $412,08 *$ & $412,08 *$ & $897,11^{*}$ & $59,78 *$ \\
\hline Condições (C) & 2 & $189,52 *$ & $189,52^{*}$ & 70,77ns & $4,33^{*}$ \\
\hline Tempo (T) & 2 & $1,37 \mathrm{~ns}$ & $1,37 \mathrm{~ns}$ & $1355,36 *$ & $4,21^{*}$ \\
\hline $\mathrm{P} * \mathrm{C}$ & 4 & $19,15 n s$ & $19,15 \mathrm{~ns}$ & 45,74ns & 1,39ns \\
\hline $\mathrm{P}^{*} \mathrm{~T}$ & 4 & $235,90 *$ & $235,90 *$ & $922,47^{*}$ & $4,63^{*}$ \\
\hline $\mathrm{C}^{*} \mathrm{~T}$ & 4 & $59,37 *$ & $59,37 *$ & $70,28 \mathrm{~ns}$ & $1,80 \mathrm{~ns}$ \\
\hline $\mathrm{P}^{*} \mathrm{C}^{*} \mathrm{~T}$ & 8 & $46,10 *$ & $46,10^{*}$ & $126,06 *$ & $0,58 \mathrm{~ns}$ \\
\hline Erro & 54 & 17,96 & 17,96 & 39,10 & 1,12 \\
\hline Média & - & 94,27 & 5,73 & 94,89 & 19,89 \\
\hline CV(\%) & - & 4,50 & 73,94 & 6,59 & 5,32 \\
\hline
\end{tabular}

* = efeito significativo em nível de $5 \%$ de probabilidade de erro, pelo teste $\mathrm{F}{ }^{\text {ns }}$ = efeito não significativo pelo teste $\mathrm{F}$.

Ciência Rural, v.38, n.4, jul, 2008. 
Tabela 2 - Porcentagem de grãos normais (GN), porcentagem de grãos duros (GD), porcentagem de absorção de água (absorção) da cultivar de feijão "Pérola" avaliada em três períodos de semeadura, três locais de armazenamento e em três tempos de armazenamento. Santa Maria - RS, UFSM, 2005

\begin{tabular}{|c|c|c|c|c|c|c|c|c|c|c|c|c|}
\hline \multirow{3}{*}{$\begin{array}{c}\text { Condição de } \\
\text { armazenamento }^{2}\end{array}$} & \multicolumn{4}{|c|}{---------------GN (\%) } & \multicolumn{4}{|c|}{------------GD (\%)------------ } & \multicolumn{4}{|c|}{-----------Absorção (\%)----------- } \\
\hline & \multicolumn{4}{|c|}{ Tempo de armazenamento (meses) } & \multicolumn{4}{|c|}{ Tempo de armazenamento (meses) } & \multicolumn{4}{|c|}{ Tempo de armazenamento (meses) } \\
\hline & 0 & 3 & 6 & Média & 0 & 3 & 6 & Média & 0 & 3 & 6 & Média \\
\hline & \multicolumn{12}{|c|}{ Semeadura em 15/10/2003 } \\
\hline Ambiente & 98,66 а $\mathrm{A}$ & 94,66 ab A & 88,00 b B & 93,77 & 1,34 b A & $5,34 \mathrm{ab} A$ & 12,00 a $\mathrm{A}$ & 6,23 & 101,74 a $\mathrm{A}$ & 104,30 a $\mathrm{A}$ & 87,10 b A & 97,71 \\
\hline Câmara 1 & 98,66 а $\mathrm{A}$ & 97,33 a $\mathrm{A}$ & 89,33 b B & 95,11 & 1,34 b A & 2,67 b A & 10,67 a $\mathrm{A}$ & 4,89 & 101,74 a $\mathrm{A}$ & 106,24 a $\mathrm{A}$ & 89,78 b A & 99,25 \\
\hline Câmara 2 & 98,66 а $\mathrm{A}$ & 99,99 а A & 99,99 a $\mathrm{A}$ & 99,55 & 1,34 а $\mathrm{A}$ & 0,01 a $\mathrm{A}$ & 0,01 a B & 0,45 & 101,74 a $\mathrm{A}$ & 97,26 a A & 94,64 a $\mathrm{A}$ & 97,88 \\
\hline \multirow[t]{2}{*}{ Média } & 98,66 & 97,33 & 92,44 & 96,14 & 1,34 & 2,67 & 7,56 & 3,86 & 101,74 & 102,60 & 90,51 & 98,28 \\
\hline & \multicolumn{12}{|c|}{ Semeadura em 29/10/2003 } \\
\hline Ambiente & 99,99 а A & 96,00 a $\mathrm{A}$ & 94,66 a $A$ & 96,88 & 0,01 a $\mathrm{A}$ & 4,00 a $\mathrm{A}$ & 5,34 a $A$ & 3,12 & 107,07 a $\mathrm{A}$ & 104,63 a $A$ & $85,53 \mathrm{~b} \mathrm{~A}$ & 99,08 \\
\hline Câmara 1 & 99,99 а $\mathrm{A}$ & 93,33 ab A & 90,67 b A & 94,66 & 0,01 b A & $6,67 \mathrm{ab} A$ & 9,33 a $\mathrm{A}$ & 5,34 & 107,07 a $\mathrm{A}$ & 109,33 a $\mathrm{A}$ & 67,46 b B & 94,62 \\
\hline Câmara 2 & 99,99 а $\mathrm{A}$ & 99,99 а A & 97,33 a $A$ & 99,10 & 0,01 a $\mathrm{A}$ & 0,01 а $\mathrm{A}$ & 2,67 a $A$ & 0,90 & 107,07 a $\mathrm{A}$ & 103,51 a $\mathrm{A}$ & 91,67 b A & 100,75 \\
\hline \multirow[t]{2}{*}{ Média } & 99,99 & 96,44 & 94,22 & 96,88 & 0,01 & 3,56 & 5,78 & 3,12 & 107,07 & 105,82 & 81,55 & 98,15 \\
\hline & \multicolumn{12}{|c|}{ Semeadura em 21/11/2003 } \\
\hline Ambiente & 84,00 b A & 92,00 a $\mathrm{A}$ & 94,67 a $A$ & 90,22 & 16,00 a $\mathrm{A}$ & 8,00 b B & 5,33 b A & 9,78 & 96,72 a $\mathrm{A}$ & 73,52 b B & 90,06 a $\mathrm{A}$ & 86,77 \\
\hline Câmara 1 & 84,00 b A & 78,67 b B & 96,00 a $\mathrm{A}$ & 86,22 & 16,00 a $\mathrm{A}$ & 21,33 a $A$ & $4,00 \mathrm{~b} A$ & 13,78 & 96,72 a A & 71,34 b B & 91,69 a $\mathrm{A}$ & 86,58 \\
\hline Câmara 2 & 84,00 b A & 98,66 a $A$ & 96,00 a $\mathrm{A}$ & 92,89 & 16,00 a $\mathrm{A}$ & 1,34 b B & $4,00 \mathrm{~b} \mathrm{~A}$ & 7,11 & 96,72 a $\mathrm{A}$ & 86,09 a $\mathrm{A}$ & 91,22 a $\mathrm{A}$ & 91,34 \\
\hline Média & 84,00 & 89,78 & 95,56 & 89,78 & 16,00 & 10,22 & 4,44 & 10,22 & 96,72 & 76,99 & 90,99 & 88,23 \\
\hline
\end{tabular}

${ }^{1}$ Médias de tratamentos não seguidas de mesma letra (minúsculas na horizontal e maiúsculas na vertical) diferem em nível de 5\% de probabilidade de erro pelo teste de Duncan.

${ }^{2}$ Câmara 1: umidade relativa de 45 - 50\% e temperatura média do ar de $12^{\circ} \mathrm{C}$; câmara 2: umidade relativa de $80 \%$ e temperatura média do ar de $0,5^{\circ} \mathrm{C}$.

câmara 1, aos seis meses (Tabela 2). Quando os grãos foram obtidos na semeadura realizada em 21/11/2003, observou-se a redução da porcentagem de grãos duros com o tempo de armazenamento.

A maior porcentagem de grãos normais foi constatada nas semeaduras realizadas em 15/10/2003 e em 29/10/2003, sendo de $96,14 \%$ e de $96,88 \%$, respectivamente. Acredita-se que os altos valores obtidos nestes períodos sejam justificados pela melhor distribuição das chuvas, o que propiciou melhores condições para o desenvolvimento dos grãos, embora tenha ocorrido deficiência hídrica em período próximo a da colheita (Figura 1). Na semeadura realizada em 21/ $11 / 2003$, foi observado maior porcentagem de grãos duros (10,22\%), devido a menor disponibilidade hídrica verificada no sub-período floração-enchimento dos grãos. RIBEIRO et al. (2007) também constataram maior porcentagem de grãos hardshell quando a semeadura da cultivar "TPS Nobre" foi realizada tardiamente na época de safra no Estado do Rio Grande do Sul.

A porcentagem de absorção de água diminuiu significativamente durante o período de armazenamento dos grãos obtidos de semeaduras realizadas em 15/10/2003 e em 29/10/2003 (Tabela 2). Assim, a capacidade de hidratação dos grãos diminuiu progressivamente, pois, durante a estocagem, ocorreu a deterioração gradativa da qualidade dos grãos para o cozimento, caracterizada pelo aumento no grau de dureza dos grãos (BURR et al., 1968; ROZO et al., 1990; SARTORI, 1996). Entretanto, para a cultivar “TPS
Nobre", quando armazenada por seis meses em câmara fria com $80 \%$ de umidade relativa do ar e com temperatura de $0,5^{\circ} \mathrm{C}$, não houve alteração na porcentagem de absorção de água, o que é desejável pelo fato de não provocar alteração na integridade do tegumento dos grãos (RIBEIRO et al., 2007).

O tempo de cozimento dos grãos de feijão da cultivar "Pérola" apresentou alteração em função do período de semeadura e do tempo de armazenamento (Tabela 3). Quando os grãos foram obtidos de semeadura realizada em 15/10/2003 e em 29/10/2003, eles apresentaram tempo de cocção menor, ao longo dos seis meses de armazenamento. No entanto, isso não se repetiu quando os grãos foram obtidos de semeadura realizada em $21 / 11 / 2003$. Nessa última condição, maior tempo de cocção se faz necessário desde o início até o final do período de armazenamento dos grãos, como já observado por BURR et al. (1968) e ROZO et al. (1990). Assim, para o cozimento desses grãos, foi necessário mais tempo, o que implicou em maior gasto de energia.

Considerando que as condições climáticas no momento da colheita do grão podem interferir na integridade do tegumento, maior tempo para a absorção de água ou para o cozimento podem ser requeridos em função da qualidade dos grãos ou das condições de temperatura e de umidade de armazenamento. O programa de melhoramento precisa considerar esses fatores na seleção de cultivares de feijão de preparo mais rápido e com qualidade para o cozimento. 


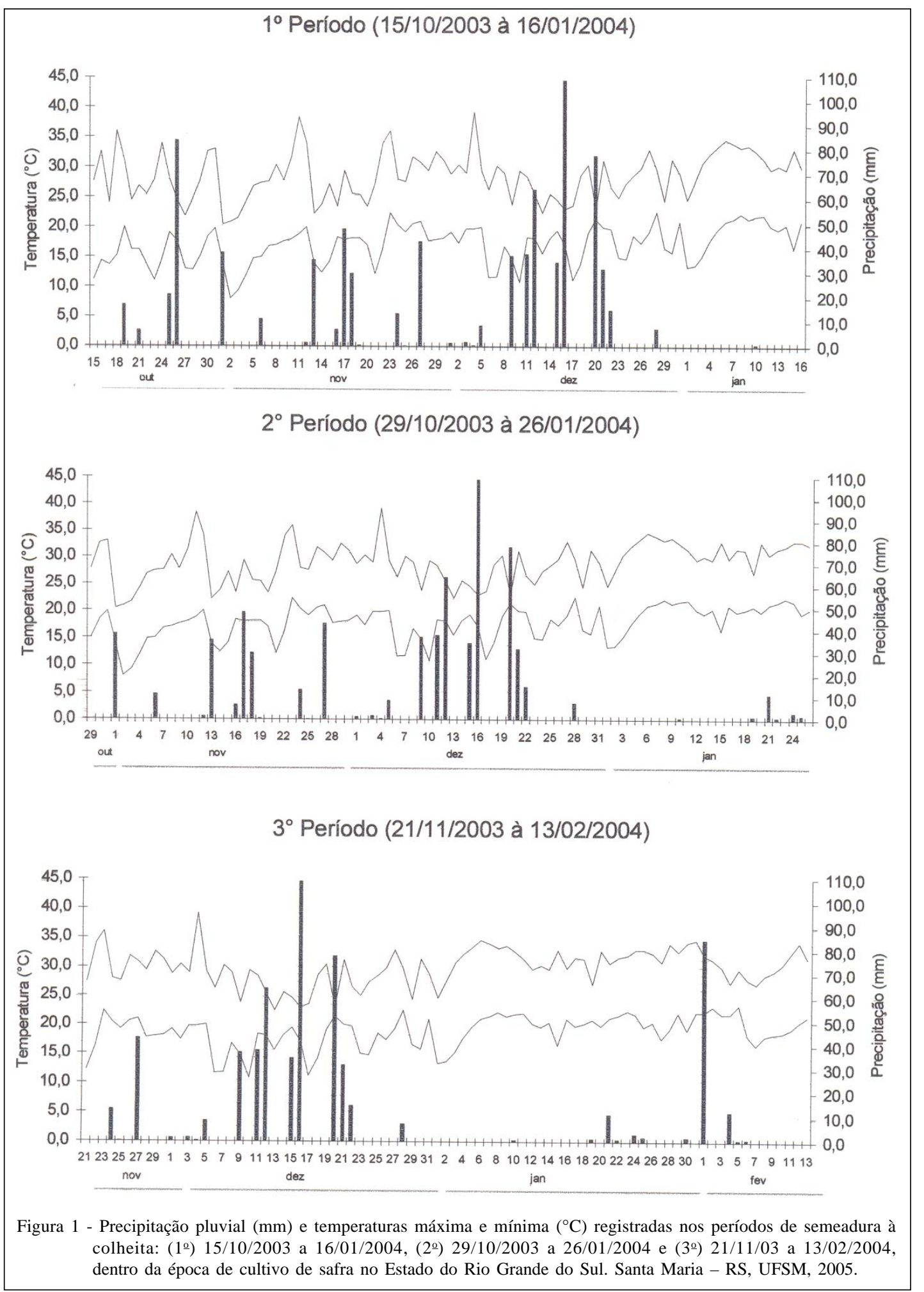

\section{CONCLUSÕES}

A semeadura de feijão realizada tardiamente no cultivo de safra do RS favorece o aumento da porcentagem de grãos duros para a cultivar "Pérola".
As características da qualidade para o cozimento dos grãos de feijão, absorção de água e o tempo de cozimento, são afetadas pelo período de semeadura, pelas condições de armazenamento 
Tabela 3 - Tempo de cozimento (minutos) de grãos de feijão da cultivar "Pérola" avaliada em três períodos de semeadura e em três tempos de armazenamento. Santa Maria - RS, UFSM, 2005

\begin{tabular}{lcccc}
\hline & \multicolumn{4}{c}{ Tempo de armazenamento (meses) ${ }^{1}$} \\
\cline { 2 - 5 } $\begin{array}{l}\text { Data de } \\
\text { semeadura }\end{array}$ & 0 & 3 & 6 & Média \\
\hline 15/10/2003 & 19,23 a B & 19,03 a B & 18,68 a B & 18,98 \\
$29 / 10 / 2003$ & 18,74 a B & 19,11 a B & 19,39 a B & 19,08 \\
$21 / 11 / 2003$ & 20,61 b A & 21,35 b A & 22,86 a A & 21,61 \\
Média & 19,53 & 19,83 & 20,31 & 19,89 \\
\hline
\end{tabular}

${ }^{1}$ Médias de tratamentos não seguidas de mesma letra (minúsculas na horizontal e maiúsculas na vertical) diferem em nível de $5 \%$ de probabilidade de erro pelo teste de Duncan.

(temperatura e umidade relativa) e pelo tempo de armazenamento.

\section{AGRADECIMENTOS}

Ao Conselho Nacional de Desenvolvimento Científico e Tecnológico (CNPq), pela concessão de bolsa à pesquisadora Nerinéia Dalfollo Ribeiro e à Fundação de Amparo à Pesquisa do Estado do Rio Grande do Sul (FAPERGS), pela bolsa do aluno Nerison Luis Poersch.

\section{REFERÊNCIAS}

BOURNE, M.C. Size density and hardshell in dry beans. Journal of Food Technology, Chicago, v.21, p.17A-20A, 1967.

BURR, H.K. et al. Cooking rates of dry beans as influenced by moisture content and temperature and time of storage. Food Technology, Chicago, v.22, n.3, p.336-338, 1968.

CARBONELL, S.A.M. et al. Qualidade tecnológica de grãos de genótipos de feijoeiro cultivados em diferentes ambientes. Bragantia, Campinas, v.62, n.3, p.369-379, 2003.

Comissão Estadual de Pesquisa de Feijão. CEPEF. Indicações técnicas para a cultura do feijão no Rio Grande do Sul 2003/04. Passo Fundo: UPF, 2003. 149p.

DALLA CORTE, A. et al. Enviroment effect on grain quality in early common bean cultivars and lines. Crop Breeding and Applied Biotechnology, Londrina, v.3, n.3, p.193-202, 2003.

GARCIA-VELA, L.A.; STANLEY, D.W. Water-holding capacity in hard-to-cook bean (P. vulgaris L.): effect of $\mathrm{pH}$ and ionic strength. Journal of Food Science, Chicago, v.54, n.4, p.1080-1081, 1989.

KIGEL, J. Culinary and nutritional quality of Phaseolus vulgaris seeds as affected by evironmental factors. Biotechnologie, Agronomie, Society et Enviroment, Jerusalém, v.3, n.4, p.205-209, 1999.
LEMOS, L.B. et al. Características agronômicas e tecnológicas de genótipos de feijão do grupo comercial Carioca. Pesquisa Agropecuária Brasileira, Brasília, v.39, n.4, p.319-326, 2004.

MOURA, A.C.C. Análises físico-químicas e enzimáticas antes e após armazenamento em grãos de feijão (Phaseolus vulgaris L.) submetidos a diferentes tempos e tipos de secagem. 1998. 70f. Dissertação (Mestrado em Ciência dos Alimentos) - Curso de Pós-graduação em Ciência dos Alimentos, Universidade Federal de Lavras, Lavras.

PLHAK, L.C. et al. Comparision of methods used to characterize water imbibition in hard-to-cook beans. Journal of Food Science, Chicago, v.54, n.3, p.326-336, 1989.

PROCTOR, J.R.; WATTS, B.M. Development of a modified Mattson bean cooker procedure based on sensory panel cookability evaluation. Canadian Institute of Food Science and Technology Journal, Apple Hill, v.20, n.1, p.9-14, 1987.

RIBEIRO, N.D. et al. Efeito de períodos de semeadura e das condições de armazenamento sobre a qualidade de grãos de feijão para o cozimento. Bragantia, Campinas, v.66, n.1, p.157163, 2007.

RODRIGUES, J.A. et al. Standardization of imbibition time of common bean grains to evaluate cooking quality. Crop Breeding and Applied Biotechnology, Viçosa, v.4, n.,4, p.465-471, 2004.

RODRIGUES, J.A. et al. Qualidade para o cozimento de grãos de feijão obtidos em diferentes épocas de semeadura. Bragantia, Campinas, v.64, n.3, p.369-376, 2005.

ROZO, C. et al. Effect of storage time, relative humidity and temperature on the cookability of whole red kidney beans and on the cell wall components of the cotyledons. Canadian Institute Food Science and Technology Journal, Apple Hill, v.23, n.1, p.72-75, 1990.

SARTORI, M.R. Armazenamento. In: ARAÚJO, S.R. et al. Cultura do feijoeiro comum no Brasil. Piracicaba: POTAFÓS, 1996. 786p. p.543-562.

SCHOLZ, M.B.S.; FONSECA JÚNIOR, N.S. Efeito de ambientes, dos genótipos e da interação genótipos $\mathrm{x}$ ambientes na qualidade tecnológica de feijão do grupo de cores no estado do Paraná. In: REUNIÃO NACIONAL DE PESQUISA DO FEIJÃO, 6., 1999, Goiânia, GO. Anais... Goiânia: Embrapa, 1999a. 880p. p.339-342.

SCHOLZ, M.B.S.; FONSECA JÚNIOR, N.S. Influência ambiental, genotípica e sua interação na qualidade tecnológica de feijão do grupo preto no Paraná. In: REUNIÃO NACIONAL DE PESQUISA DO FEIJÃO, 6., 1999, Goiânia, GO. Anais... Goiânia: Embrapa, 1999b. 880p. p.389-392.

VINDIOLA, O.L. et al. Accelerated development of the hardto-cook state in beans. Cereal Foods World, St. Paul, v.31, n.8, p.538-552, 1986 .

WYATT, J.C. Seed coat and water absorption properties of seed of nearisigenic snap bean lines differing in seed coat color Journal of the American Society for Horticultural Science, Saint Joseph, v.102, n.4, p.478-480, 1977. 